\title{
Hydroalcoholic and polyphenolic extracts of Ziziphus jujuba mill fruits prevent methyl methanesulfonate-induced DNA damage in HepG2 cells
}

\author{
Mahmoud Etebari $^{{ }^{*}}$, Behzad Zolfaghari ${ }^{2}$, Abbas Jafarian-Dehkordi ${ }^{1}$, Afsaneh Mirzaei ${ }^{1}$ \\ ${ }^{1}$ Department of Pharmacology and Toxicology, Isfahan Pharmaceutical Sciences Research Center, School of \\ Pharmacy and Pharmaceutical Sciences, Isfahan University of Medical Sciences, Isfahan, Iran. \\ ${ }^{2}$ Department of Pharmacognosy, Isfahan Pharmaceutical Sciences Research Center, School of Pharmacy and \\ Pharmaceutical Sciences, Isfahan University of Medical Sciences, Isfahan, Iran
}

Received: July 26, 2015, Revised: Aug 1, 2015, Accepted: Aug 31, 2015

\begin{abstract}
Ziziphus jujuba Mill (ZJ), which has been extensively used by the Iranian traditional healers, belongs to the Ramnaceae family. This semitropical herb contains large quantities of polyphenols and flavonoids, which in turn reveal antioxidant, antibacterial, free radical scavengering, and several other pharmacological activities. The purpose of the present study was to evaluate the DNA damage prevention potential of hydroalcoholic and polyphenolic extracts of Ziziphus jujuba on HepG2 cells. Throughout the assessment of genoprotective properties, cells were incubated with various concentrations of hydroalcoholic $(0.1,1,10$, and $50 \mu \mathrm{g} / \mathrm{ml})$ and polyphenolic extracts $(0.1$ and $1 \mu \mathrm{g} / \mathrm{ml})$ for a one-hour period, followed by a one-hour incubation period with genotoxic concentration of methyl methanesulfonate (MMS) $(10 \mu \mathrm{M})$. The comet assay method was applied because of its being attributable to the substantial sensitivity, its inexpensiveness, and its straightforward procedure of use. The tail length, percentage of DNA in tail, and tail moment were measured. Statistical analysis revealed that concentrations of 10

polyphenolic extract were genoprotective against MMS. Therefore, our results suggest that Ziziphus jujuba at suitable doses can prevent DNA damage.
\end{abstract}

Keywords: Ziziphus jujuba, genoprotective effect, HepG2, Comet Assay.

Pharm Biomed Res 2015; 1(3): 20-30

DOI: 10.18869/acadpub.pbr.1.3.20

\section{Introduction}

Constantly, cells undergo destructive oxidative stress processes, which could originate either from exogenous or endogenous sources. Cells withstand this occurrence through engaging several distinct defense mechanisms ranging from free radical scavengers such as glutathione (GSH), vitamins $\mathrm{C}$, and antioxidant enzymes to the elaborate DNA repair systems (1). Genetic alterations to the DNA both in somatic and germ cells can induce a plethora of events, from single-point mutations to chromosomal break, rearrangements or loss, which finally lead to several genetic-related diseases among which is also cancer (2). In order to identify genotoxic molecules, researchers perform specified assays contributing DNA damage in toxically affected cells. Loss of excision repair, cross-linking, alkali-labile sites, point mutations, structural and numerical chromosomal aberrations, and the compromised integrity of the genetic material have been known as the leading 
causes of carcinogenesis (3). In line with the results of preceding assessments, following a healthy diet guarantees genomic stability (4). Biomolecules found in fruits and vegetables might play a protective role in several conditions such as cancers. Revealing safer profiles has placed the naturally occurring antioxidants in a more pleasurable position than synthetic ones. Thus, the correlation between the consumption of fruits and vegetables and decreased vulnerability to cardiovascular diseases and cancer has been manifested by the existing epidemiological evidence. On account of this fact, the evaluation of genoprotective activity of fruits and vegetables has substantially attracted attentions, and a large bulk of research had been carried out (4-6).

One such medicinal plant is Ziziphus jujuba, which belongs to the Ramnaceae family and contains several flavonoids such as querarin, 6"'-feruloylspinosin, apigenin6-C-b-d-glucopyranoside, spinosin 6'"'feruloylisospinosin, isospinosin, and isovitexin-200-O-b-d-glucopyranoside (7, 8). Additionally, a large number of phytochemicals such as 64 alkaloids, 16 glycosides, and 14 terpenoids also can be found with certain proportions in this plant. Among them, phenolic components, flavonoids, triterpenic acids, and polysaccharides are considered as efficacious radical scavengers which could exhibit potent antioxidant, anticarcinogenic, and anti-inflammatory activities which finally lead to maintaining a more stable genomic content $(4,9,14)$.

Each ingredient has unique and multifactorial properties, one of the most prominent of which is its ability to limit or slow down oxidative stress reactions (9). Different parts of Ziziphus jujuba have been established to provide a wide range of therapeutic properties such as carminative, expectorant, and antidiabetic. In traditional medicine, fruits and seeds of Ziziphus jujuba have been widely used as tonic and aphrodisiac and sometimes as sedativehypnotic, anxiolytic, antiulcer, antiinflammatory, antispastic, antifertility/contraception, antinephritic, cardiotonic, immunostimulant, and wound healing properties (9-14).

Assessing both genotoxicity and subsequent carcinogenicity as well as analyzing the defense and opposing protocols are fundamental prerequisites for the evaluation of pharmaceuticals. A number of fully defined in vitro and in vivo testing techniques are available in order to measure genotoxic and carcinogenic phenomenon (2).

The comet assay or SCGE (single cell gel electrophoresis) is a simple, sensitive, versatile, feasible, and economical genotoxicity measuring procedure and a specific process to detect deoxyribonucleic acid strand breaks in individual eukaryotic cells. The number of studies applying this method rises every year $(15,16)$. Indeed, the International Workshop on Genotoxicity Testing regards the in vitro SCGE in the 3-D skin model as a valuable support to genotoxicity identification as: (a) it is independent of cell proliferation, and (b) it covers a broader spectrum of DNA damage. Ostling and Johason developed the new method of quantifying DNA damage and repair with the goal of utilization in cellular studies which imports the word

name implied data was analyzed by a software (Comet score) to provide the protocol with a higher definition sensitivity $(2,17,18)$.

Methyl methanesulfonate (MMS) is the most common methylating agent which, for years, has been applied as an experimental research chemical. MMS acts through modification in both guanine and adenine to create base mispairing and replication 
blocks, respectively. DNA-related destructions caused by alkylating agents would principally be retrieved via the base excision repair (BER) pathway and DNA alkyltransferase actions (19, 20). In the present study, we used HepG2 cells (hepatoma cells) for specialized liver function and comparable activities with human hepatocytes (21).

Based on the aforementioned research findings, this research aimed to investigate the genoprotective activities anticipated from hydroalcoholic and polyphenolic extracts of Ziziphus jujuba on HepG2 cells against MMS toxicity by taking advantage of the SCGE method. Additionally, according to each extract, the genotoxic features would be specified individually. And, the correlation between DNA damage quantity and various concentrations of this herbal extract would be mentioned illustratively.

\section{Materials and Methods}

\section{Materials}

Ethanol, Chloroform, EDTA, $\mathrm{H}_{2} \mathrm{O}_{2}, \mathrm{NaCl}$, $\mathrm{NaOH}, \quad \mathrm{Na} 2 \mathrm{CO}_{3}, \quad \mathrm{NaH} 2 \mathrm{PO}_{4}, \quad$ Folin Ciocalteu reagent (FCR), Tris, and Triton X-100 were acquired from Merck Co. (Germany). Low melting point agarose (LMA), $\mathrm{Na}_{2} \mathrm{HPO}_{4}, \quad \mathrm{KCl}, \quad$ methyl methanesulfonate (MMS), and ethidium bromide were from Sigma Co. (USA). Normal melting point agarose (NMA) was supplied by Cinnagen Co. (Iran). The RPMI 1640 medium and fetal bovine serum (FBS) were obtained from Capricorn (Austria), and antibiotic was purchased from PAA Co. (Austria). And, HepG2 cells came from Pasture Institute (Iran). The Ziziphus jujuba fruits were purchased from a local medicine market in Isfahan (Isfahan province, Iran) in November 2013 and authenticated by Pharmacognosy Department of Isfahan Pharmacy School as Ziziphus jujuba. A sample of plant is deposited in our school for future evidence (Herbarium number: 1893).

\section{Extract Preparation}

The Ziziphus jujuba fruits were carefully cut into slices. The small cut slices were air-dried at room temperature, then powdered, and extracted with $500 \mathrm{ml}$ of $70 \%$ aqueous $\mathrm{EtOH}$ through maceration (48 hours for two times) at room temperature to obtain hydroalcoholic extract. Then, all the extract was evaporated in a rotating evaporator and was freezedried. Pulverized pulp (100 g) of Ziziphus jujuba was extracted in two steps; first, with EtOH: $\mathrm{H}_{2} \mathrm{O}$ with a proportion of $90 \%$ (v/v) and then with EtOH: $\mathrm{H}_{2} \mathrm{O}$ with a proportion of $50 \%(\mathrm{v} / \mathrm{v})$. At each step, a sufficient amount of solvent was added to make liquid slurry, and the mixture was left for 12 hours. The resultant product was filtered by Büchner funnel under vacuum condition and then was freeze-dried. The two extracts were then combined and evaporated to $1 / 3$ of the original volume. The resultant aqueous extract was first cleared by extraction (in a separating funnel) with chloroform and was then evaporated to be completely dried under vacuum in a rotary evaporator and freezedryer (22-24).

\section{Cell Culture}

In the present research, human hepatoma (HepG2) cells were applied to find the genotoxicity and genoprotective effect of Ziziphus jujuba. The HepG2 cell line was obtained from Pasture Institute of Iran and was maintained in RPMI medium (containing 7\% fetal bovine serum and 1\% penicillin/streptomycin to avoid the growth of unwanted and pathogenic bacterial microorganisms) and was incubated in a humidified atmosphere of $95 \%$ air in micro filter plates To select the lowest genotoxic dose, HepG2 cells were incubated with 
different concentrations of MMS, for 1 hour. A series of concentrations in the

diluting the stock solution $(11.82 \mathrm{M})$ with RPMI. Then, Cells were incubated with different concentrations of extracts followed by a one-hour period of incubation with selected concentration of MMS in 12-wells plates. After that, the upper medium of wells was thrown away and washed with PBS. After trypsinization, $1 \mathrm{ml}$ of medium was added to each falcon tube to be utilized for the next stages of the SCGE. For implementing SCGE, at least $90 \%$ of viability was required (24-26).

\section{Alkaline Comet Assay}

The comet assay (SCGE) is a gel electrophoresis method that is used to visualize and measure DNA strand breaks in individual cells using microscope. In its simplest form, incubated cell suspensions $\left(0.25 \times 10^{6}\right.$ cells per well $)$ were mixed with $1 \%$ LMP agarose $\left(37^{\circ} \mathrm{C}\right)$. Then, they were placed on the precoated slides (1\% NMP agarose). Afterwards, they were embedded on a microscope slide, and they were covered by cover glasses for 5 minutes and then they were immersed in a lysis solution $(\mathrm{pH}=10.0)$ for 40 minutes and rinsed with distilled water to remove lipids and proteins. To run the electrophoresis protocol, the slides were put in a weak buffer ( $\mathrm{pH}>13.0$, for 40 minutes) in order to separate broken DNA. After electrophoresis was done, $25 \mathrm{~V}$ with an electricity current adjusted to $300 \mathrm{~mA}$, DNA was stained using a fluorescent dye

5 minutes,

then washed in ice-cold medium or phosphate buffered saline, and viewed using under $\times 400$ magnification using a fluorescence microscope with an excitation filter of $510-560 \mathrm{~nm}$ and barrier filter of $590 \mathrm{~nm}$. All stages of SCGE were performed at dark conditions, and all solutions were prepared freshly and used cool. Individual images can then be digitized and analyzed for informative properties such as the distance that the DNA has migrated and the percentage of DNA that has migrated. These features give an indication of the number of strand breaks present in the cell $(16,24,25,27,28)$.

\section{Folin-Ciocalteu method for measurement of total phenolic content}

$20 \mu \mathrm{L}$ extract $5 \mathrm{~g} / \mathrm{l}$ was added to $1.58 \mathrm{~mL}$ deionized water into test tubes and $100 \mu \mathrm{L}$ Folin-Ciocalteu reagents were mixed. Then $300 \mu \mathrm{L}$ of $20 \%$ sodium carbonate solution was added to the mixtures. The tubes were mixed, and then were allowed to incubate for $2 \mathrm{~h}$ at $20{ }^{\circ} \mathrm{C}$. The absorbance of the resulting blue color was measured by colorimetric at $765 \mathrm{~nm}$. A calibration curve of Gallic acid (ranging from $50 \mathrm{mg} / \mathrm{l}$ to $500 \mathrm{mg} / \mathrm{l}$ ) was prepared (31).

\section{Statistical Analysis}

Based on this research, the most common parameters analyzed are tail length (the length of the comet tail), the percentage of DNA in the tail (percentage of colored spots in tail), and tail moment (percentage of DNA in tail $\times$ tail length). The percentage of DNA in the tail is generally defined as the amount of DNA in the tail divided by the amount of DNA in the cell multiplied by 100 , while the tail length is the distance from the middle or the estimated perimeter of the comet head to the last visible signal in the tail. These factors were used for statistical analysis in this investigation $(15,29)$. The raw data that were obtained by comet score software were imparted as means \pm SD (standard deviation), three continuous quantitative variables (comet length, percentage of DNA in tail, and tail moment) were analyzed, and post hoc test (Tukey) was performed on raw data to determine 
significant differences between concentrations. Statistical analysis was accomplished by IBM-SPSS software, USA.

\section{Results}

In order to determine protective effects of hydroalcoholic and polyphenolic extracts of Ziziphus jujuba on genotoxicity induced by MMS, HepG2 cells were incubated with different concentrations of extracts for 1 hour followed by a one-hour incubation period for MMS $(10 \mu \mathrm{M})$. The results of SCGE after the one-hour incubation period for both extracts were analyzed. One-way analysis of variance (ANOVA) for the tail length extracts was significant $(\mathrm{p}<0.001)$. According to the results of Tukey's multiple comparison post hoc test, all concentrations have decreased the tail length significantly $(p<0.001)$ in comparison with the MMS group. The results of one-way ANOVA for the percentage of DNA in tail were significant $(p<0.001)$. Based on the results of the Tukey's multiple comparison post hoc test, in all concentrations of both extracts the percentage of DNA in tail decreased significantly $(p<0.001)$ compared to the MMS group. The result of one-way ANOVA of the tail moment for all groups was significant $(p<0.001)$. Moreover, the results of Tukey's multiple comparison post hoc test for all concentrations showed a significant decrease $(p<0.001)$ in this parameter compared to the MMS group.

\section{SCGE Results of Different Concentrations of $M M S$}

In order to determine genotoxic concentration of MMS, HepG2 cells were incubated with different concentrations of $1,5,10,100$, and $500 \mu \mathrm{M}$ for 1 hour followed by the SCGE. Regarding the results of this step, the best concentration of MMS $(10 \mu \mathrm{M})$ had significant difference with the control group (Fig. 1). In addition, the number of incubated cells showed no decrease during incubation. Hence, this concentration was selected for the next stage of the study. At first, the minimum amount of genotoxic concentration of MMS was determined. The statistical outcomes showed significant differences between concentrations of 10, 100, and 500

(p 0.05) was selected as the minimum amount of genotoxic concentration of MMS.

\section{Studying Genotoxic and Genoprotective Effects of Extract of ZJ Combined with $M M S$}

Three repetitions of SCGE were performed for each extract concentration and analysis was implemented on at least 100 cells per slide. To determine the genotoxic effects, concentrations were contrasted with negative control, and significant differences were manifested by (*) sign.

Subsequently, genotoxic effects of hydroalcoholic extract (data not shown) were surveyed in various concentrations (1, 10,100 ,

concentrations and negative control, and drastically different from negative control

and lower concentrations were safe and had no genotoxic effect (Table 1). Consequently, genoprotective effects of hydroalcoholic extract were determined in 1, 10, and 50

cellular exposure was performed with preincubation of cells with these concentrations for 1 hour. Then, HepG2 cells were incubated by minimum genotoxic concentration of MMS as

Results manifested significant differences 


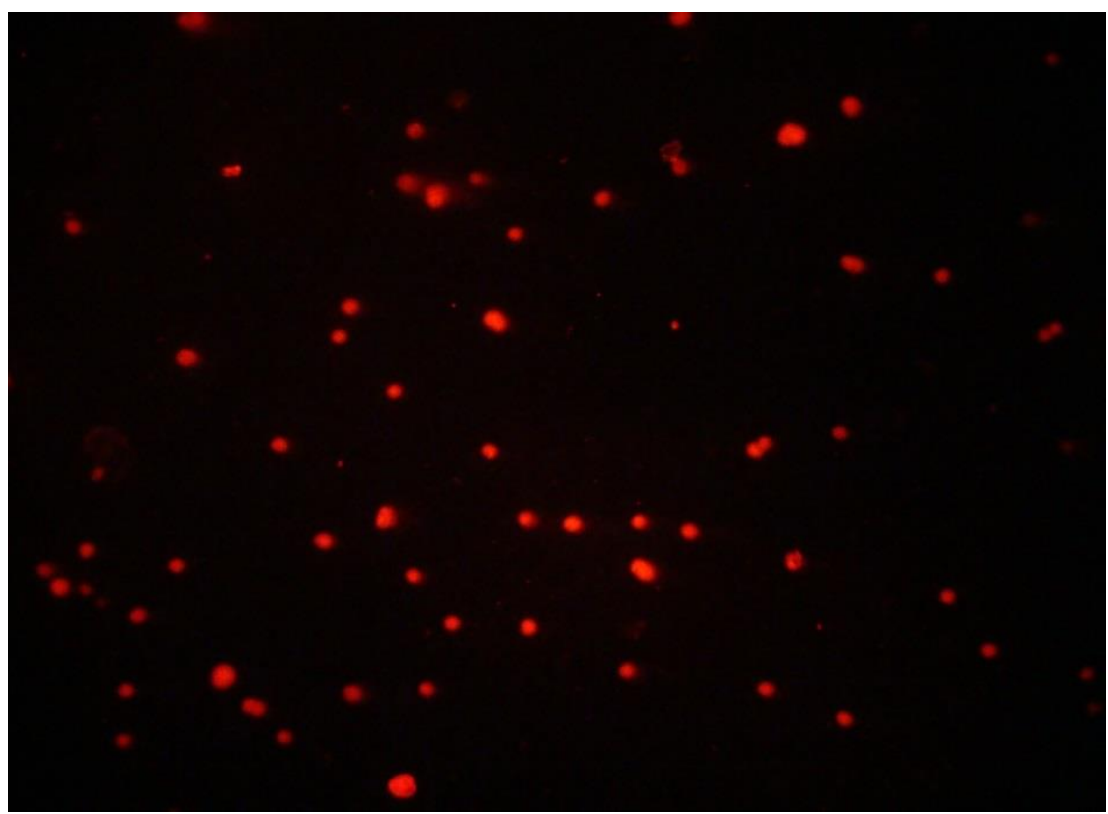

A

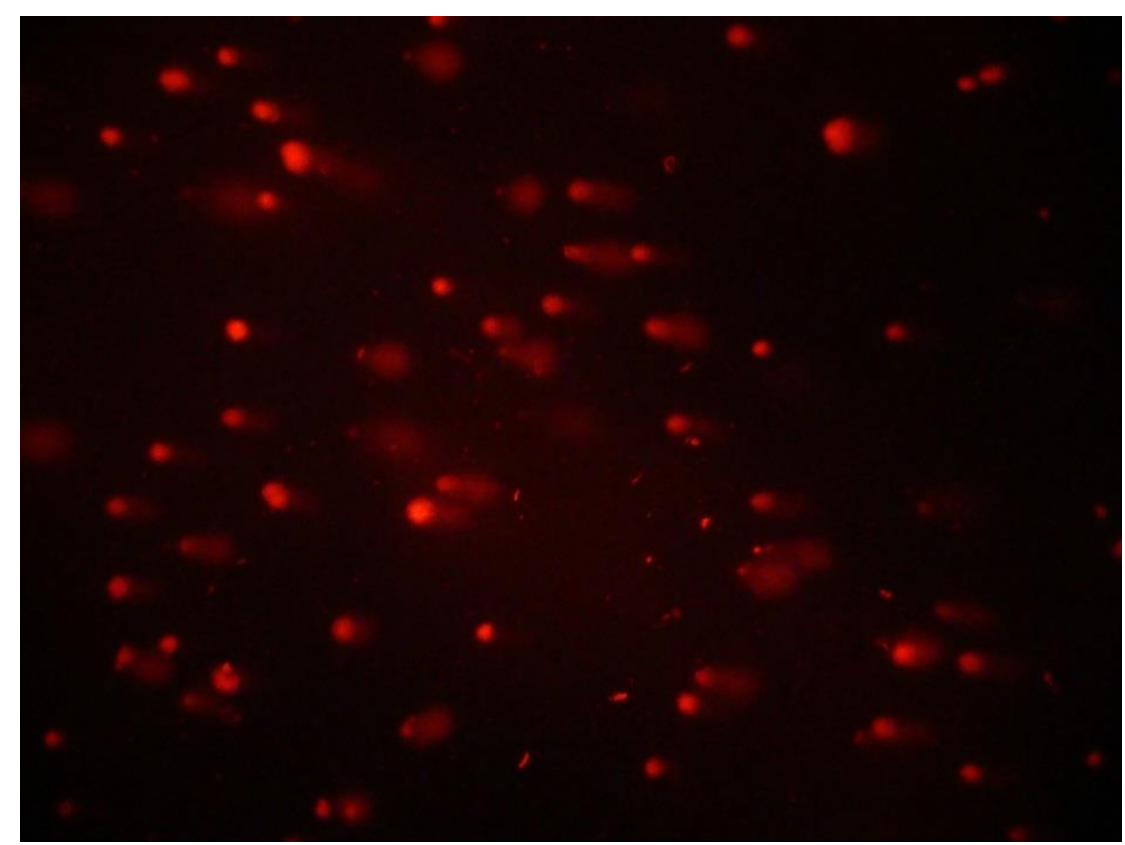

B

Figure 1 A) Comet image of untreated HepG2 cells as negative control. B) Comet image of HepG2 cells treated with $10 \mu \mathrm{M}$ of MMS as positive control 
Table1 Genotoxic effects of Ziziphus jujuba Mill extracts on HepG2 cells

\begin{tabular}{|c|c|c|c|c|}
\hline Treatment & $\begin{array}{l}\text { Concentration } \\
(\mu \mathrm{g} / \mathrm{ml})\end{array}$ & $\begin{array}{c}\text { Tail } \\
\text { length(pixels) } \\
\text { '(Mean } \pm \text { SD })\end{array}$ & $\begin{array}{l}\text { \%DNA in tail } \\
(\text { Mean } \pm \text { SD })\end{array}$ & $\begin{array}{c}\text { Tail } \\
\text { moment(pixels) } \\
(\text { Mean } \pm \text { SD })\end{array}$ \\
\hline \multirow{5}{*}{$\begin{array}{c}\text { Hydroalcoholic } \\
\text { extract }\end{array}$} & $\begin{array}{l}\text { Negative control } \\
\text { (PBS) }\end{array}$ & $0.56 \pm 0.03$ & $0.09 \pm 0.14$ & $0.0007 \pm 0.002$ \\
\hline & 1 & $0.96 \pm 0.37$ & $0.27 \pm 0.81$ & $0,007 \pm 0.035$ \\
\hline & 10 & $4.4 \pm 1.1$ & $2.5 \pm 0.8$ & $0.3 \pm 0.27$ \\
\hline & 100 & $60.9 \pm 0.6^{*}$ & $22.8 \pm 2.1 *$ & $18.8 \pm .6^{*}$ \\
\hline & 500 & $98 \pm 2.7 *$ & $22 \pm 1.7 *$ & $29 \pm 2.6^{*}$ \\
\hline \multirow{5}{*}{$\begin{array}{c}\text { Polyphenolic } \\
\text { extract }\end{array}$} & $\begin{array}{l}\text { Negative control } \\
\text { (PBS) }\end{array}$ & $1.64 \pm 0.18$ & $0.46 \pm .94$ & $0.02 \pm 0.09$ \\
\hline & 1 & $1.52 \pm 0.6$ & $0.97 \pm 0.18$ & $0.03 \pm 0.04$ \\
\hline & 10 & $51.7 \pm 2.6^{*}$ & $24.9 \pm 2.9 *$ & $14.4 \pm 2.2^{*}$ \\
\hline & 100 & $108 \pm 6.9 *$ & $38 \pm 2^{*}$ & $44 \pm 4^{*}$ \\
\hline & 500 & $131 \pm 6.2^{*}$ & $52 \pm 1.2 *$ & $70 \pm 1.3^{*}$ \\
\hline
\end{tabular}

The effect of genotoxic concentrations of hydroalcoholic and polyphenolic extract of Ziziphus jujuba ( $\mu \mathrm{g} / \mathrm{ml})$ in comparison with negative control on tail length (pixels), \%DNA in tail, and tail moment (pixels) of 3 independent experiments are represented as mean \pm SD. Significant difference $(p<0.001)$ was illustrated by $(*)$ sign.

$\mu \mathrm{M}$ of MMS, and mentioned concentration had genoprotective effects on MMS 0.001).

After this step, genotoxic effects of various concentrations of polyphenolic extract (1,

Therefore, a meaningful difference was negative control, and the lower concentrations were safe and had no genotoxic effect (Table 1). Afterwards, genoprotective effects of this extract were determined by various concentrations $(0.1$, 1 concentrations had genoprotective effects consistent with positive control and the 1

protection (Table 2).

Total phenolic content of extracts According to the Folin-Ciocalteu method, total amount of phenolic content assayed, and total phenolic content of the 
Table 2 Genoprotective effects of Ziziphus jujuba Mill on HepG2 cells using the comet assav

\begin{tabular}{|c|c|c|c|c|}
\hline Treatment & $\begin{array}{l}\text { Concentration } \\
\text { range }(\mu \mathrm{g} / \mathrm{ml})\end{array}$ & $\begin{array}{c}\text { Tail length } \\
\text { (pixels) } \\
\text { (Mean } \pm \text { SD) }\end{array}$ & $\begin{array}{c}\text { \%DNA in } \\
\text { tail } \\
(\text { Mean } \pm \text { SD })\end{array}$ & $\begin{array}{l}\text { Tail moment } \\
\text { (pixels) } \\
\text { (Mean } \pm \text { SD) }\end{array}$ \\
\hline \multirow{4}{*}{$\begin{array}{l}\text { Iydroalcoholic } \\
\text { extract }\end{array}$} & $\begin{array}{c}\text { Positive control } \\
\qquad(M M S)\end{array}$ & $107 \pm 3.8$ & $39 \pm 2.6$ & $46 \pm 6.1$ \\
\hline & 1 & $8.9 \pm 1.1 *$ & $11 \pm 1.3^{*}$ & $2.4 \pm 0.04^{*}$ \\
\hline & 10 & $6.8 \pm 0.8^{*}$ & $6.5 \pm 0.5^{*}$ & $0.8 \pm 0.3^{*}$ \\
\hline & 50 & $85 \pm 0.5$ & $28.7 \pm 0,8$ & $28.8 \pm 2.9$ \\
\hline \multirow{3}{*}{$\begin{array}{c}\text { Polyphenolic } \\
\text { extract }\end{array}$} & $\begin{array}{c}\text { Positive control } \\
\qquad(M M S)\end{array}$ & $107 \pm 5.3$ & $49 \pm 2.5$ & $57 \pm 5.1$ \\
\hline & 0.1 & $104 \pm 6.1$ & $33 \pm 2.7$ & $39 \pm 5.3$ \\
\hline & 1 & $8.4 \pm 0.1^{*}$ & $7.5 \pm 6.8^{*}$ & $1 \pm 0.4^{*}$ \\
\hline
\end{tabular}

\footnotetext{
The effect of genoprotective concentrations of hydroalcoholic and polyphenolic extract of Ziziphus jujuba compared with control groups on tail length (pixels), percentage of DNA in tail, and tail moment (pixels) that are represented as mean \pm SD. * Mean value was significantly different from control 01) one-way ANOVA followed by post hoc test).
}

hydroalcoholic and polyphenolic extracts was reported to be $1.8 \%$ and $2.8 \%$ of Gallic acid, receptively. All experiments were performed in triplicate.

\section{Discussion}

The objective of this cellular toxicity analysis was to assess the distinct concentration ranges of Ziziphus jujuba extracts in order to demonstrate whether they possess either genoprotectivity or genotoxicity features. Different parts of Ziziphus jujuba fruit could be considered as a rich source of antioxidant and antiproliferative compounds including cyclopeptide alkaloids, flavonoids, sterols, jujuboside A, jujuboside B, lauric acid, triterpenoid saponins, ascorbic acid, anthocyanines, and polyphenolic components which play roles in genomic stability and in the reduction of internal or external oxidant. Therefore, it is supposed 
to be an appropriate preventive agent against cancerous disorders besides any free radical-related body dysfunction $(9,10,30$, 31).As illustrated by the result of the present study, it is noteworthy to mention that Ziziphus jujuba extract would be genoprotective and genotoxic for the cell DNA, which depends on the concentration and the type of solvent used. Some extracts cause DNA damage and induce cell death and show anti-cancer effects (32). In accordance with the results, and also attending the SCGE method accuracy and sensitivity as well as selected concentration (each of these could be an error source and regarded as limitations for the present study), hydroalcoholic and polyphenolic extract had shown genotoxic effect in 100

concentrations below the genotoxic ones, there are biologically active components in hydroalcoholic extract that exhibited doserelated protective behavior against MMSinduced DNA damage where 1 and 10 reduction in tail length, the percentage of DNA in tail, and tail moment comparing to positive control. The

probably MMS genotoxicity stands over the protective effect of this specific herb. This could be deduced in two rationalities as antioxidant capacity reduction or genotoxic properties commence. Based on our data,

regarded genotoxic. Therefore, genomic protective ability was analyzed in 1 and 0.1 table 2 indicates, the best concentration for producing genoprotective aspects is

significantly different from positive control.

\section{Conclusion}

When comparing these two extracts, due to the higher antioxidant and genoprotective ability revealed in lower concentrations by the polyphenolic solution, it would be regarded as a more potent complex against genomic content instability.

\section{Acknowledgements}

This paper was derived from a pharmacy thesis in Isfahan University of Medical Sciences, Isfahan, Iran. We would like to express our gratitude to the research department of Isfahan University of Medical Sciences, Isfahan, I.R. Iran, for the cooperation and financial supports.

\section{Conflict of interest}

The authors declare that they have no conflict of interest.

\section{References}

1. Kryston TB, Georgiev AB, Pissis P, Georgakilas AG. Role of oxidative stress and DNA damage in human carcinogenesis. Mutat Res 2011;711:193-201.

2. Madia F, Phrakonkham P, Corvi R. Current and Emerging In Vitro Methods for Genotoxicity

and Carcinogenicity. In: Bal-Price A, Jennings P. In Vitro Toxicology Systems. $1^{\text {st }}$ ed. Springer New York; 2014. p. 307-32.

3. Nagarathna P, Wesley MJ, Reddy PS, Reena K. Review on Genotoxicity, its Molecular 
Mechanisms and Prevention. Int J Pharm Sci Rev Res 2013;22:236-43.

4. Zhang H, Jiang L, Ye S, Ye Y, Ren F Systematic evaluation of antioxidant capacities of the ethanolic extract of different tissues of jujube (Ziziphus jujuba Mill.) from China. Food Chem Toxicol 2010;48:1461-5.

5. Cheng D, Zhu C, Cao J, Jiang W. The protective effects of polyphenols from jujube peel (Ziziphus Jujube Mill) on isoproterenol-induced myocardial ischemia and aluminum-induced oxidative damage in rats. Food Chem Toxicol 2012;50:1302-8

6. Li J-W, Fan L-P, Ding S-D, Ding X-L. Nutritional composition of five cultivars of Chinese jujube. Food Chem 2007;103:454-60.

7. Cheng G, Bai Y, Zhao Y, Tao J, Liu Y, Tu G, et al. Flavonoids from Ziziphus jujuba Mill var. spinosa. Tetrahedron 2000;56:8915-20.

8. Pawlowska AM, Camangi F, Bader A, Braca A. Flavonoids of Zizyphus jujuba L. and Zizyphus spina-christi (L.) Willd (Rhamnaceae) fruits. Food Chem 2009;112:858-62.

9. Preeti, Tripathi S. A phytopharmacological Ziziphus jujuba Int J Res Dev Pharm L Sci 2014;3:959-66.

10. Hung CF, Hsu BY, Chang SC, Chen B-H. Antiproliferation of melanoma cells by polysaccharide isolated from Zizyphus jujuba. Nutrition 2012;28:98-105.

11. Jaydari F, Johari $H$, Taati $M$, Asadian $P$, Alirezaei M, Sheikhzadeh F. The effects of Ziziphus jujuba fruit extract on catalase activity and lipid peroxidation in the heart and erythrocytes of rats following chronic ethanol consumption. Iran J Vet Res 2011;5:179-83.

12. Jafarian A, Zolfaghari $B$, Shirani $K$ Cytotoxicity of different extracts of arial parts of Ziziphus spina-christi on HeLa and MDA-MB468 tumor cells. Adv Biomed Res 2014;3:38.

13. Benammar C, Hichami A, Yessoufou A, Simonin A-M, Belarbi $M$, Allali $H$, et al. Zizyphus lotus L.(Desf.) modulates antioxidant activity and human T-cell proliferation. BMC Complement Altern Med 2010;10:54.

14. Mahajan R, Chopda M. Phyto-Pharmacology of Ziziphus jujuba Mill-A plant review. Pharmacogn Rev 2009;3:320-29.

15. Collins AR. The comet assay for DNA damage and repair. Mol Biotechnol 2004;26:249-61.

16. Liao W, McNutt MA, Zhu W-G. The comet assay: a sensitive method for detecting DNA damage in individual cells. Methods 2009;48:46-53.

17. Singh NP, McCoy MT, Tice RR, Schneider EL. A simple technique for quantitation of low levels of DNA damage in individual cells. Exp Cell Res 1988;175:184-91.

18.

-platform

public domain PC image-analysis program for the comet assay. Mutat Res 2003;534:15-20.
19. Lundin $C$, North $M$, Erixon $K$, Walters $K$, Jenssen D, Goldman AS, et al. Methyl methanesulfonate (MMS) produces heat-labile DNA damage but no detectable in DNA doublestrand breaks. Nucleic Acids Res 2005;33:3799811.

20. Drabløs F, Feyzi E, Aas PA, Vaagbø CB, Kavli $\mathrm{B}$, Bratlie MS, et al. Alkylation damage in DNA and RNA repair mechanisms and medical significance. DNA repair 2004;3:1389-407.

21. Uhl M, Helma C, Knasmüller S. Evaluation of the single cell gel electrophoresis assay with human hepatoma (HepG2) cells. Mutat Res 2000;468:213-25.

22. Conforti F, Sosa S, Marrelli M, Menichini F, Statti GA, Uzunov D, et al. In vivo antiinflammatory and in vitro antioxidant activities of Mediterranean dietary plants. J Ethnopharmacol 2008;116:144-51.

23. Sajjadi SE, Atar AM, Yektaian A. Antihyperlipidemic effect of hydroalcoholic extract, and polyphenolic fraction from Dracocephalum kotschyi Boiss. Pharm Acta Helv 1998;73:167-70.

24. Etebari M, Zolfaghari B, Jafarian-Dehkordi A, Rakian R. Evaluation of DNA damage of hydroalcoholic and aqueous extract of Echium amoenum and Nardostachys jatamansi. J Res Med Sci 2012;17:782-6.

25. Etebari M, Ghannadi A, Jafarian-Dehkordi A, Ahmadi F. Genotoxicity evaluation of aqueous extracts of co-toneaster discolor and Alhagi pseudalhagi by comet assay. J Res Med Sci 2012;17:237-241.

26. Zhang L-H, Kamanna VS, Zhang MC, Kashyap ML. Niacin inhibits surface expression of ATP

for raising HDL. J Lipid Res 2008;49:1195-201.

27. Mozaffarieh $M$, Schoetzau A, Sauter M, Grieshaber M, Orgül S, Golubnitschaja O, et al. Comet assay analysis of single stranded DNA breaks in circulating leukocytes of glaucoma patients. Mol Vis 2008;14:1584-8.

28. Tavakoli M, Bateni E, Rismanchian M, Fathi M, Doostmohammadi A, Rabiei A, et al. Genotoxicity effects of nano bioactive glass and Novabone bioglass on gingival fibroblasts using single cell gel electrophoresis (comet assay): An in vitro study. Dent Res J 2012;9:314-20.

29. Burlinson B, Tice RR, Speit G, Agurell E, Brendler-Schwaab SY, Collins AR, et al. Fourth International Workgroup on Genotoxicity testing: results of the in vivo Comet assay workgroup. Mutat Res 2007;627:31-5.

30. Pahuja M, Mehla J, Reeta K, Joshi S, Gupta YK. Hydroalcoholic extract of Zizyphus jujuba ameliorates seizures, oxidative stress, and cognitive impairment in experimental models of 
epilepsy in rats. Epilepsy Behav 2011;21:35663.

31. Xue Z, Feng W, Cao J, Cao D, Jiang W. Antioxidant activity and total phenolic contents in peel and pulp of Chinese jujube (Ziziphus jujuba Mill) fruits. J Food Biochem 2009;33:613-29.

32. Huang $X$, Kojima-Yuasa $A$, Norikura $T$, Kennedy DO, Hasuma T, Matsui-Yuasa I. Mechanism of the anti-cancer activity of Zizyphus jujuba in HepG2 cells. Am J Chin Med. 2007;35:517-32. 